\title{
Ring expansions of 1-azabicyclo[n.1.0]alkanes. Recent developments
}

\author{
Dmytro O. Tymoshenko \\ AMRI, 26 Corporate Circle, Albany, NY 12203, USA \\ E-mail:Dmytro.tym@gmail.com
}

\begin{abstract}
In the past decade ring expansion of aziridines and aziridiniums fused to other rings has developed into an attractive alternative method to classical pyrrolidine, piperidine and azepine ring construction approaches. This short review provides an update on recent reports and demonstrates the usefulness and the efficiency of this approach.
\end{abstract}

Keywords: 1-Azabicyclo[n.1.0]alkanes, ring expansion, aziridine, aziridinium

\section{Table of Contents}

1. Introduction

2. Ring Expansions of 1-Azabicyclo[2.1.0]pentanes

3. Ring Expansions of 1-Azabicyclo[3.1.0]hexanes

4. Ring Expansions of 1-Azabicyclo[4.1.0]heptanes and 1-Azabicyclo[5.1.0]octanes

5. Ring Expansions of Aziridines Fused to Bridged and Bicyclic Ring Systems

6. Summary

7. Acknowledgments

8. References

\section{Introduction}

Non-aromatic aza-heterocycles, such as pyrrolidines, piperidines and azepines, their benzo-, spiro-, bridged and polycyclic derivatives can be found in numerous natural products. They represent a vast variety of cyclic and substitution patterns. Their synthesis, properties, biological activity and isolation from the natural products are well-documented. ${ }^{1 \mathrm{a}-\mathrm{d}}$ Several recent reviews have been published covering pharmaceutically active compounds, ${ }^{2}$ spiro-derivatives, ${ }^{3 a-b}$ marine alkaloids, ${ }^{4}$ iminosugar di- and oligosaccharides, ${ }^{5 a-b}$ and alkaloid lipids. ${ }^{6}$ Advances in synthetic methods include catalytic asymmetric aza Diels-Alder reactions, ${ }^{7}$ benzotriazole mediated syntheses, ${ }^{8}$ asymmetric synthesis, ${ }^{9 a-b}$ and cyclization of allylsilyl-substituted $N$-acyliminium and 
iminium ions. ${ }^{10}$ A special case of the preparation of $n$-membered non-aromatic azacycles is a ring expansion of ( $n-1)$ cyclic precursors fused to aziridine ring. Thus, azabicyclo[3.1.0]hexane $2(\mathrm{n}=$ 1 ), ${ }^{1 \mathrm{a}-\mathrm{b}}$ serves as a reactive precursor to piperidine 3 (Figure 1). Additional $N$-diversification in aziridinium species $(\mathrm{R} \neq \mathrm{H})$ is a valuable source of $N$-substituted derivatives.

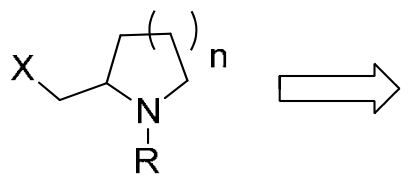

1

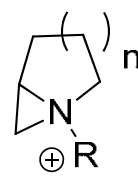

2

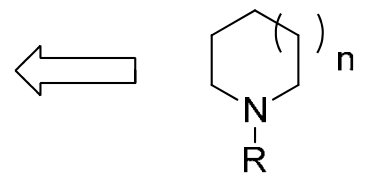

3

\section{Figure 1}

Bicycles 4 are expected to meet the general reactivity profile of aziridines, ${ }^{12}$ (Scheme 1 ) with the unfavorable predominant formation of 2-aminomethyl derivatives 5 due to nucleophilic attack on the least substituted C2-carbon. Strain of the fused ring, nature of the nucleophile and catalyst can significantly further affect the process. Additionally, the high reactivity of the species 2 makes isolation of fused aziridines and aziridiniums difficult to achieve. Nevertheless, ring expansion methodology is of continuous interest as it provides vast opportunities for the transfer of substitution patterns and stereochemistry from more accessible smaller ( $n$ - 1$)$ rings onto $n$-membered aza-cycles.

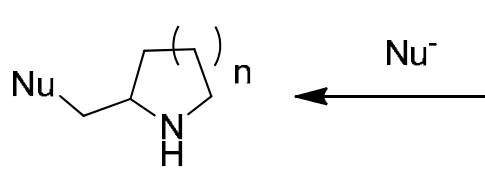

5

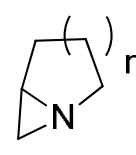

4

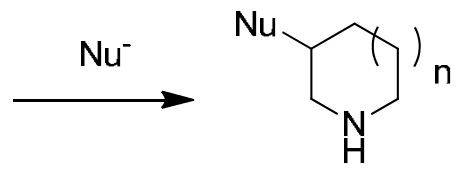

6

\section{Scheme 1}

The current account surveys the literature from 2001 until 2010 on ring enlargement of the systems $2(n=1)$ and includes results of a deeper retrospective literature search for other azabicyclo[3.1.0]alkanes $(n \neq 1)$. The discussion is organized in the order of ring sizes followed by reactivity of aziridines fused to bridged and polycyclic systems.

\section{Ring Expansions of 1-Azabicyclo[2.1.0]pentanes}

High energy for the strained 1-azabicyclo[2.1.0]pentane $2(n=0)$ results in its instability and isolatable entities are quite rare. ${ }^{13}$ At the same time high reactivity of the precursors 1 results in the desired ring expansion process. A series of 2-( $\alpha$-hydroxyalkyl)azetidines 7 with a variety of 
substituents both on the four-membered ring and on the adjacent hydroxy group are treated with either thionyl chloride or methanesulfonyl chloride in the presence of triethylamine (Scheme 2). The obtained intermediate 2 - $\alpha$-chloro- or 2- $\alpha$-methanesulfonyloxyalkyl azetidines rearrange stereospecifically providing good to excellent yields of 3-(chloro- or methanesulfonyloxy)pyrrolidines 8. Thus, a single isomer of the highly substituted pyrrolidine $\mathbf{9}$ was reported in $77 \%$ isolated yield. When this rearrangement is conducted in the presence of nucleophile $\left(\mathrm{NaN}_{3}, \mathrm{KCN}, \mathrm{KOH}\right.$, or $\left.\mathrm{NaOAc}\right)$, the produced pyrrolidines 10 stereospecifically incorporate the added nucleophile at $\mathrm{C}-3 .{ }^{14 \mathrm{a}-\mathrm{b}}$ The relative configuration of the substituents in the formed pyrrolidines is consistent with a mechanism involving the formation of an intermediate bicyclic aziridinium ion, which is opened regioselectively at the bridgehead carbon atom. ${ }^{14 \mathrm{~b}}$

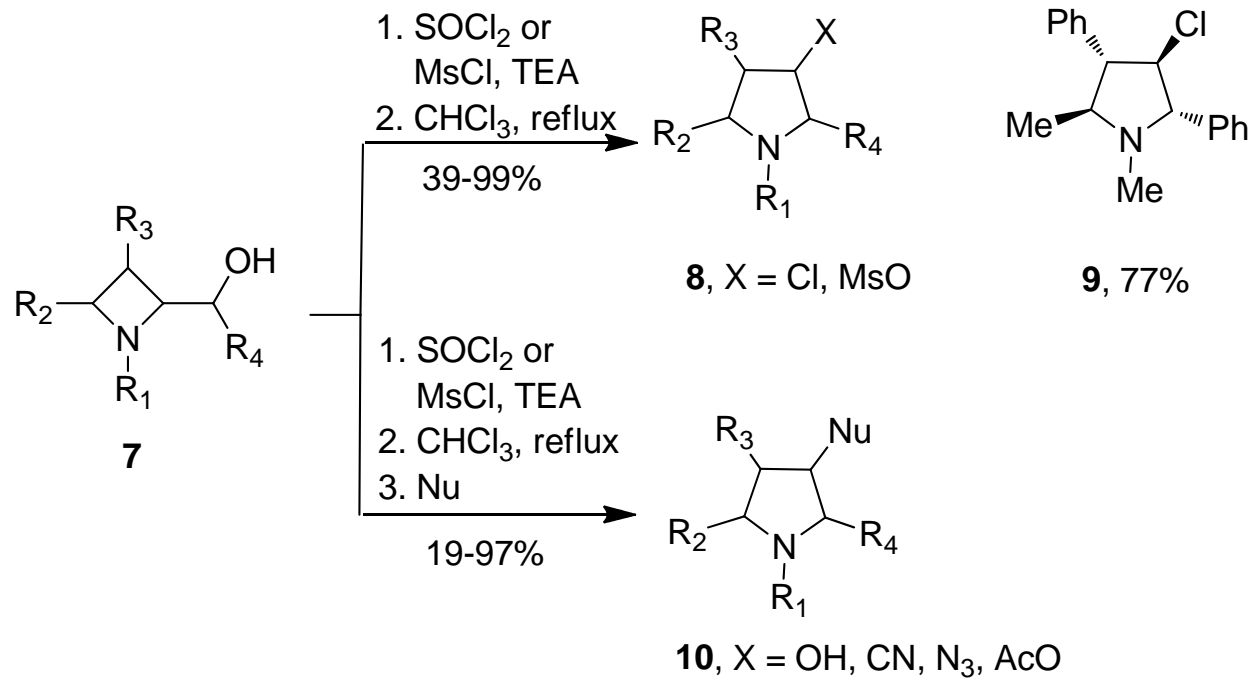

\section{Scheme 2}

Enantiopure 2-hydroxyalkylazetidine 11 when treated with DAST $(N, N$-diethylaminosulfur trifluoride) rearranged into 3-fluoropyrrolidines $\mathbf{1 3}$ (Scheme 3). The reaction is stereospecific and involves a 1-azabicyclo[2.1.0]pentane intermediate 12 which is regioselectively opened by a fluoride anion. ${ }^{15}$

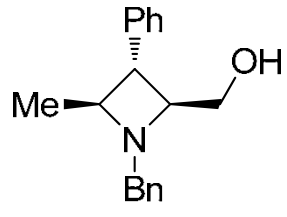

11
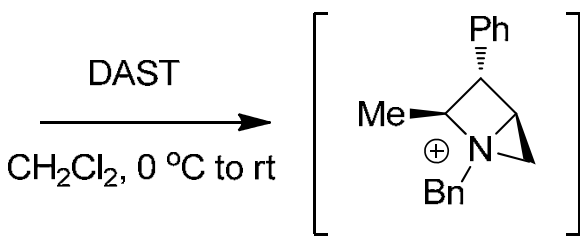

12

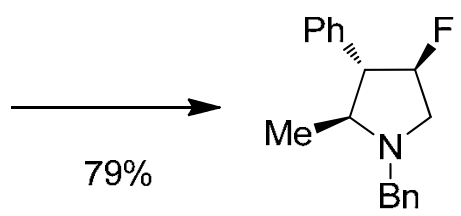

13

\section{Scheme 3}




\section{Ring Expansions of 1-Azabicyclo[3.1.0]hexanes}

Since an early report by Fuson and Zirkle, ${ }^{16}$ ring expansion of 2-substituted pyrrolidines through 1-azabicyclo[3.1.0] hexane intermediates become a useful synthetic tool and the reader is referred to the preceding reviews. ${ }^{11 a-b}$ Recent reports include further developments of functionalized mono- and polycyclic systems.

Substituted silyl compounds 15a-c were prepared from the corresponding prolinols 14 by well-established treatment with trifluoroacetic anhydride followed by the addition of triethylamine and then by treatment with sodium hydroxide (Scheme 4) ${ }^{17 \mathrm{a}-\mathrm{c}}$ Subsequent reaction and protection/deprotection steps resulted in $\mathrm{N}$-tert-Bu-piperidine $\mathbf{1 7}$ which was applied as a catalyst for enantioselective addition of diethylzinc to aldehydes. ${ }^{17 \mathrm{a}}$ 3,5-Di-TBDMSO-piperidine $16\left(\mathrm{R}_{1}=\mathrm{R}_{2}=\right.$ TBDMS $)$ can further undergo oxidation with $C$-phenyl- $N$-phenylsulfonyl oxaziridine to produce corresponding nitrone 18, a valuable intermediate for the corresponding protected dihydroxyindolizidinone $\mathbf{1 9}{ }^{17 \mathrm{~b}}$ Similarly prepared intermediate $\mathbf{1 5 a}$ was further used for the synthesis of piperidine based peptide nucleic acids. ${ }^{17}$<smiles>[R6][C@H]1C[C@@H](O)CN(Br)C1</smiles>

15a, $\mathrm{R}=\mathrm{TBDMS}, 82 \%$

15b, $R=$ TBDPS, $64 \%$

$15 \mathrm{c}, \mathrm{R}=\mathrm{TIPS}, 47 \%$
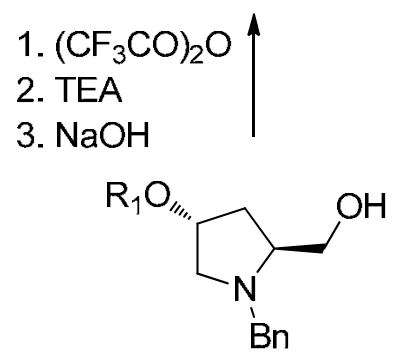

14

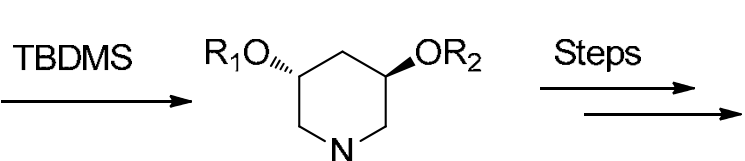

Bn 16

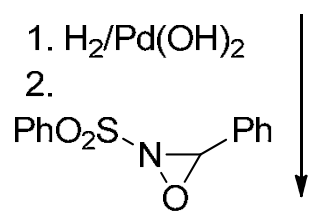<smiles>[R6]C(C)CC</smiles>

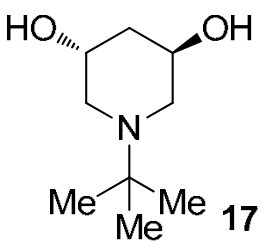

17

\section{Scheme 4}

In a similar manner (Scheme 5), ${ }^{18}$ successive $O$-activation of the protected hydroxyprolinederivatives 20a (trans) and 20b (cis) followed by nucleophilic displacement using LiCN resulted in formation of the nitriles 21a and 21b in 51 and 70\% yield, respectively. Under the reported reaction conditions $\left(\mathrm{DMF}, 0{ }^{\circ} \mathrm{C}\right.$ to $\mathrm{rt}$ ) rearrangement occurs only to a minor extent giving the piperidine derivatives $22 \mathbf{a}-\mathbf{b}$ as side products. In the case of the trans-substituted derivatives, the pyrrolidine- and the piperidine-derivatives were formed in a 7:3 mixture of isomers. For the cisisomers 4:1 ratio was observed. 


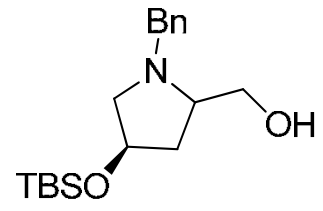

20a, trans $20 \mathrm{~b}$, cis
1. $\mathrm{Ms}_{2} \mathrm{O}, \mathrm{TEA}$, $\mathrm{CHCl}_{3}, 0^{\circ} \mathrm{C}$

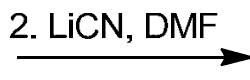

2. LiCN, DMF

TBSO

21a, trans, $51 \%$ 21b, cis, $70 \%$<smiles>N#CC1CC(O[AsH3])CN(Cc2ccccc2)C1</smiles>

22a, trans, $18 \%$ 22b, cis, $17 \%$

\section{Scheme 5}

Attempted Swern oxidation of spiro-2-(bromomethyl)pyrrolidine 23 into corresponding 2aldehyde (DMSO, $30{ }^{\circ} \mathrm{C}, 14 \mathrm{~h}, 2$ equiv of potassium carbonate) resulted in piperidin-3-one 26 instead (Scheme 6). ${ }^{19}$ The addition of potassium carbonate appeared to be essential, as piperidin3-one 26 was isolated in very low yields (10\%) if no $\mathrm{K}_{2} \mathrm{CO}_{3}$ was used. According to the suggested mechanism 2-(bromomethyl) pyrrolidines 23 are first transformed into intermediate bicyclic aziridinium salts $\mathbf{2 4}$ which are converted into piperidines $\mathbf{2 6}$ upon ring opening with dimethylsulfoxide. The last step of the proposed mechanism could occur either via direct nucleophilic ring opening at the less substituted aziridine carbon atom or via spontaneous ring opening and subsequent substitution of the formed carbenium ion. Abstraction of the acidic proton at the oxygenated carbon atom in intermediate 25 by potassium carbonate is important for further liberation of dimethylsulfide and formation of final piperidin-3-ones 26.

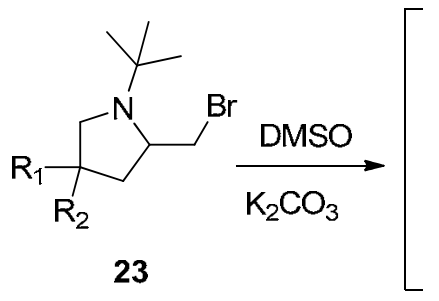

24

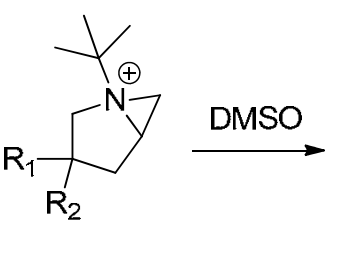

24

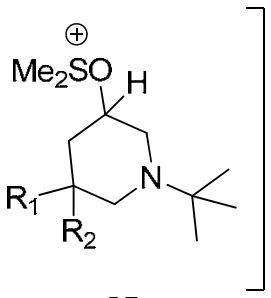

25

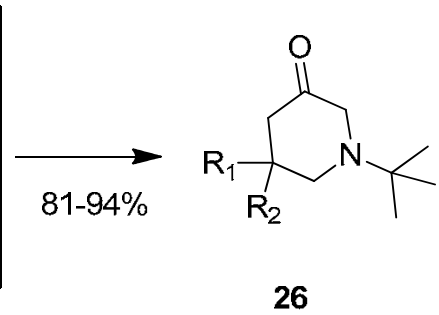

26

$$
\mathrm{R}_{1}, \mathrm{R}_{2} \text { - alkyl }
$$

\section{Scheme 6}

Synthesis of enantiopure cis-decahydroquinoline $\mathbf{2 8}$ is performed in a straightforward manner staring from octahydroindole 27 (Scheme 7). ${ }^{20}$ As above, reaction conditions include $\mathrm{O}-$ trifluoroacetylation to form a better leaving group followed by rearrangement in the presence of hydroxy anion as a nucleophile. Interestingly, when hydroxyl group activation is achieved through mesylation, the chloride anion serves as an internally generated nucleophile resulting in high yield of 3-chloro decahydroquinoline which can be subsequently transformed into an acetoxy derivative 29. 


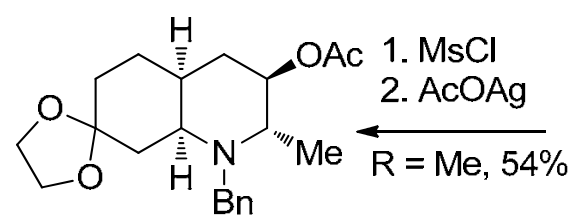

29

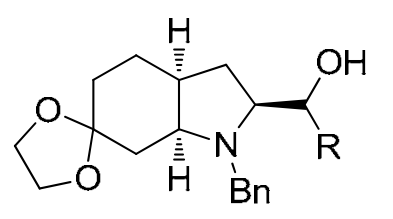

27

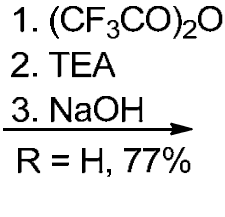

1. $\left(\mathrm{CF}_{3} \mathrm{CO}\right)_{2} \mathrm{O}$<smiles>O[C@H]1C[C@@H]2CCC3(C[C@H]2[C@@H]1Cc1ccccc1)OCCO3</smiles>

28

\section{Scheme 7}

As previously described for azabicyclopentanes, DAST is a reagent of choice for conversion of the active prolinols 30 into enantiopure 3-fluoropiperidines 33. The reaction proceeds via aziridinium intermediate 32 and usually produces mixtures of the desired piperidines 33 with 2fluoromethyl pyrrolidines 34 of variable ratios (Scheme 8). ${ }^{21 a-b}$ In the case of C-2-alkylsubstituted prolinols 30c-d and $N$-trityl prolinol 30e piperidines 33c-e form exclusively. The authors explain such selectivity by an increase in the length of the $\mathrm{C}-2-\mathrm{N}$ bond in the aziridinium intermediate 32. Stabilization of a partial positive charge at quaternary $\mathrm{C}-2$ correlates with a weakened $\mathrm{C}-2-\mathrm{N}$ bond. This results in the nucleophilic attack of the fluoride at the more electrophilic carbon and the cleavage of the $\mathrm{C}-2-\mathrm{N}$ bond. The selectivity of the rearrangement when the nitrogen atom is substituted by a bulky protecting group can also be explained in terms of lengthening of the $\mathrm{C}-2-\mathrm{N}$ bond due to steric constraints.
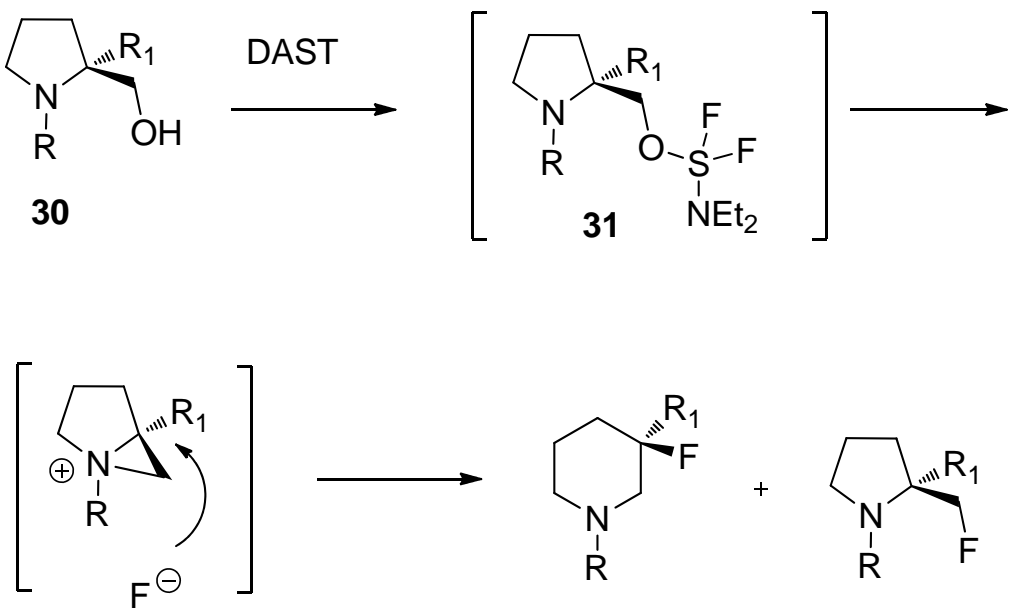

32

33

34

\begin{tabular}{llllrr} 
& $\mathrm{R}$ & $\mathrm{R}_{1}$ & Yield, \% & $\mathbf{3 3}$ & $\mathbf{3 4}$ \\
\hline a & $\mathrm{Bn}$ & $\mathrm{H}$ & 61 & 80 & 20 \\
b & $\mathrm{CH}_{2}-t-\mathrm{Bu}$ & $\mathrm{H}$ & 54 & 60 & 40 \\
c & $\mathrm{CH}_{2}-t-\mathrm{Bu}$ & $\mathrm{Et}$ & 76 & 100 & 0 \\
d & $\mathrm{CH}_{2}-t-\mathrm{Bu}$ & $\mathrm{Bn}$ & 87 & 100 & 0 \\
e & $\mathrm{CPh}_{3}$ & $\mathrm{H}$ & 64 & 100 & 0
\end{tabular}

Scheme 8 
Other examples of the ring expansion of appropriately substituted prolinols to 3-substituted piperidines include (Figure 2) the synthesis of 3-OAc derivative $35(46 \%),{ }^{22}$ tetrahydroquinoline 36 (91\%, 3:1 mixture with indoline 37) ${ }^{23} 3$-aminomethyl piperidine $38(33 \%),{ }^{24}$ thiazole 39, as a precursor of glycosidase inhibitor 1-deoxynojirimycin $(46 \%),{ }^{25}$ ester $40 \quad(84 \%),{ }^{26}$ and chloromethyl derivative $41(55 \%){ }^{27}$

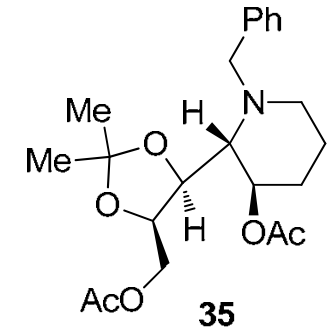

PO

38
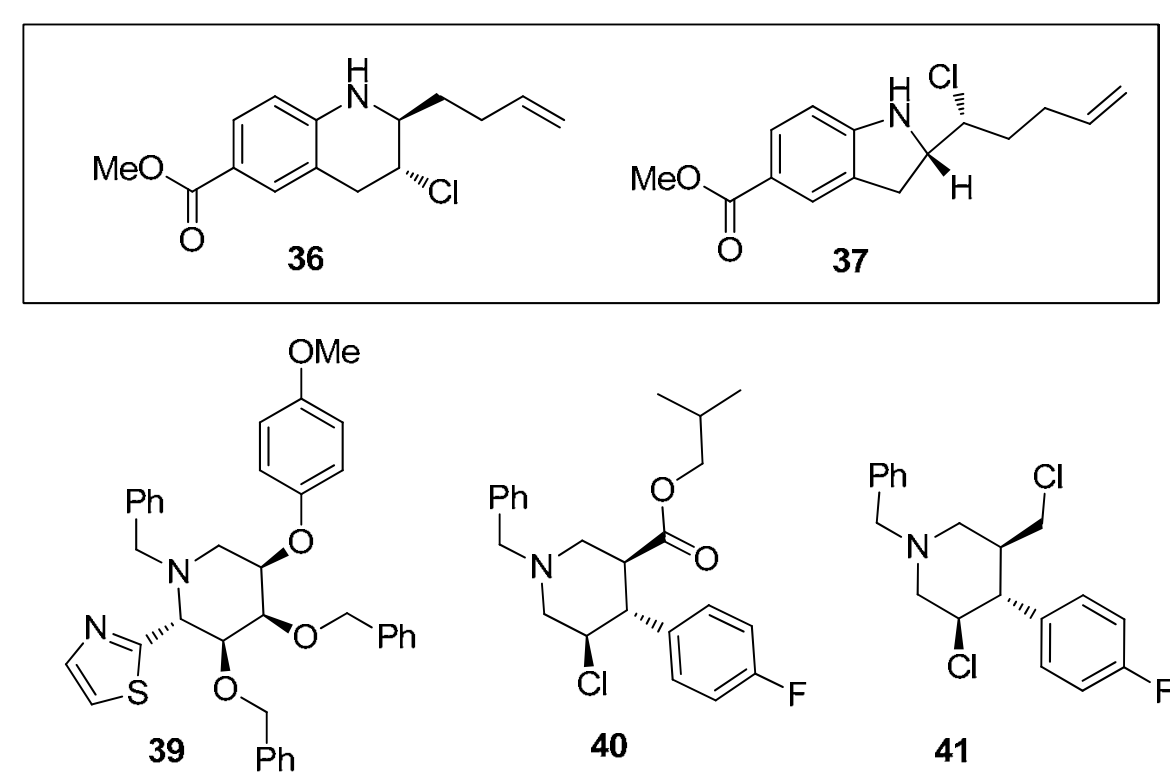<smiles>CC(C)COC(=O)C1CN(Cc2ccccc2)CC(Cl)[C@H]1c1ccc(F)cc1</smiles>

40<smiles>Fc1ccc([C@H]2C(Cl)CN(Cc3ccccc3)C[C@H]2CCl)cc1</smiles>

41

Figure 2

Noteworthy is an alternative method for fused aziridine intermediate preparation involving $2 \mathrm{H}$-azirines as precursors. Thus, 4-nitrophenyl substituted azirine 42, prepared in three steps starting from 4-nitrostyrene, is a highly reactive 1,3-dipolarophile due to the ring strain. Cycloadducts $\mathbf{4 4}$ derived from azirine and oxazolidinone $\mathbf{4 3}$ incorporates a highly strained $\mathrm{C}-\mathrm{N}$ bond within 2,6-diazatricyclo[4.2.0.0 $\left.0^{2,4}\right]$ octan-7-one ring system 44. Subsequent reduction is followed by ditosylation/cleavage of the strained $\mathrm{C}(4)-\mathrm{N}(2)$ bond and produces 1-azacepham (1,5-diazabicyclo[4.2.0] octan-8-one) derivative 45 in 34\% yield over two steps (Scheme 9). ${ }^{28}$

Although of less practical significance, azirines can serve as a source of ylides 47 which are suitable reagents for cycloadditions with dipolarophiles.

Dimethyl 2,2-difluoro-1-azabicyclo[3.1.0]hex-3-ene 3,4-dicarboxylates 48 are relatively stable and can be stored at $-20{ }^{\circ} \mathrm{C}$, but (on prolonged storage at room temperature) undergo ring expansion followed by defluorination/aromatization to 2-fluoropyridine derivatives $\mathbf{4 9}$ in high yields (Scheme 10). ${ }^{29 a-b}$ 


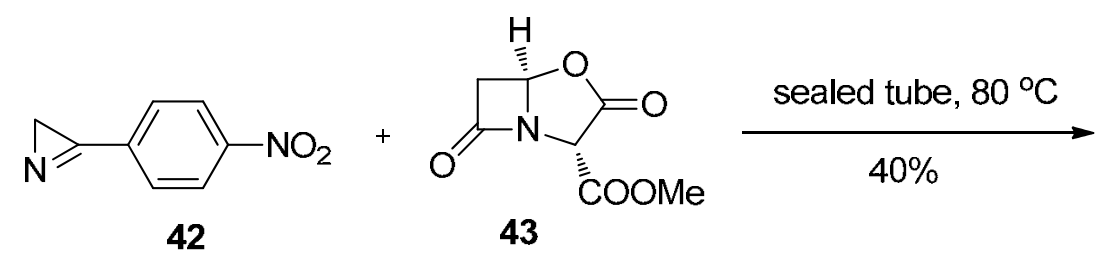<smiles>COC(=O)[C@@H]1N2C(=O)C[C@H]2N2C[C@@]12c1ccc([N+](=O)[O-])cc1</smiles>

44
1. $\mathrm{H}_{2}, \mathrm{Pd}$, EtOAc

2. TsCl, pyridine, $\mathrm{CH}_{2} \mathrm{Cl}_{2}$ $34 \%$ over 2 steps<smiles>[3H]N1C[C@H](c2ccc(N[15F])cc2)[C@@H](C(=O)OC)N2C(=O)C[C@H]12</smiles>

45

Scheme 9<smiles>[R]c1ccc(C2=NC2)cc1</smiles>

46<smiles>[R]c1ccc(C2C3CCCC32C(C)(F)F)cc1</smiles><smiles>COCC#CC(=O)OC</smiles><smiles>[R]OC(=O)C1=C(C(C)=O)C(F)(F)N2CC12c1ccc([R])cc1</smiles>

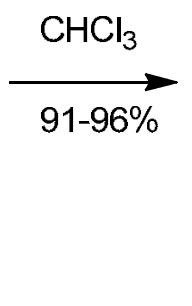<smiles>[R]OC(=O)c1c(-c2ccc([R])cc2)cnc(F)c1C(=O)OC</smiles>

$\mathrm{R}=\mathrm{H}, \mathrm{Cl}, \mathrm{Br}, \mathrm{Me}, \mathrm{MeO}$

\section{Scheme 10}

\section{Ring Expansions of 1-Azabicyclo[4.1.0]heptanes and 1-azabicyclo[5.1.0] octanes}

A number of recent publications covers ring expansion of aziridines fused to the medium rings. Thus, similarly to substituted prolinols (Scheme 8, section 2) 3-fluoroazepanes 51 are exclusive $\left(\mathrm{R}_{1} \neq \mathrm{H}\right)$ products of 2-hydroxymethylpiperidines 50 ring expansion (Scheme 11). ${ }^{21 \mathrm{~b}}$ Compound 50a $\left(R_{1}=H\right)$, unsubstituted at position 2, results upon treatment with DAST in mixture of the corresponding 3-fluoroazepane 51a and fluoromethyl derivative 52a. 


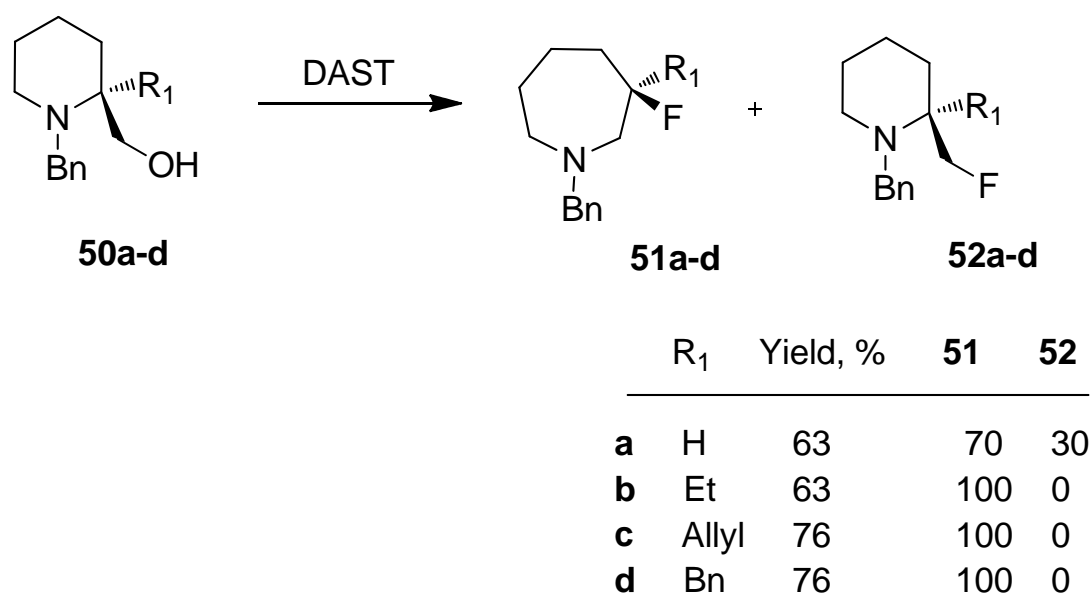

\section{Scheme 11}

Reaction of the alcohol 53 with methanesulfonyl chloride and subsequently with $\mathrm{KCN}$ in DMSO at room temperature provided 1,4-diazepane derivative 56 as a minor product (11\% yield) along with the major cyanomethyl derivative 55 (54\% yield). Surprisingly, in addition to these main products, careful chromatographic separation provided the isomeric nitrile $59(0.4 \%)$. The formation of the isomeric nitriles $\mathbf{5 5}$ and $\mathbf{5 6}$ is apparent through intermediate aziridinium ion 54. Chloride anion generated during mesylation step competes with cyanide and forms chloro diazepane 57. The latter undergoes formation of regioisomeric aziridinium ion $\mathbf{5 8}$ and subsequent cyanide attack to afford small but detectable amounts of compound 59 (Scheme 12). ${ }^{30}$

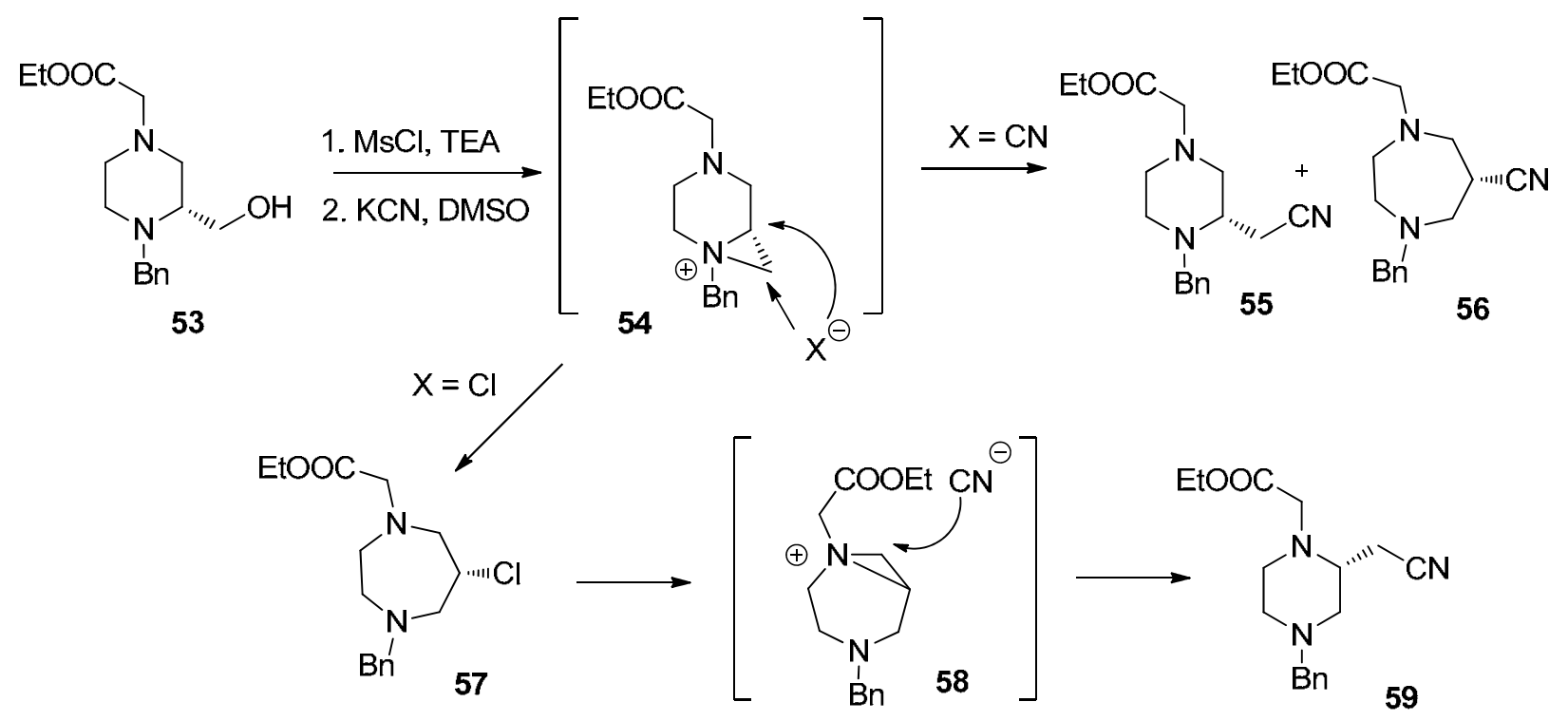

\section{Scheme 12}


Mesylate 60a and tosylate 60b when treated with $\mathrm{NaCN}$ in DMF or acetonitrile produce 4substituted 6-tosyl-2,3,4,5-tetrahydro-1H-1,3-diazepin-2-ones $\mathbf{6 1}$. Reaction in acetonitrile requires addition of 18-crown-6 ether. The process apparently proceed through an aziridine intermediate, although an alternative route is theorized by authors. In a similar fashion, mesylate 60a was reacted with sodium thiophenolate to give diazepinone 61b in 97\% yield (Scheme 13). ${ }^{31}$<smiles>[R]OCC1NC(=O)NC(C)=C1[3H]</smiles>

60a, $R_{1}=M s$

$60 \mathrm{~b}, \mathrm{R}_{1}=\mathrm{Ts}$

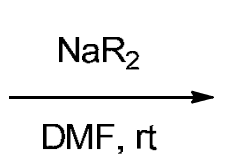

61a, $\mathrm{R}_{2}=\mathrm{CN}, 95 \%$ (from 60a)

61a, $R_{2}=C N, 89 \%$ (from 60b)

61b, $R_{2}=S P h, 97 \%$ (from 60a)

\section{Scheme 13}

Ring opening of 1,1-dichloro-1a-phenyl-1a,2-dihydro- $1 H$-azirino[1,2- $d]$ benzo[b][1,4]oxazine 62a $(\mathrm{X}=\mathrm{O})$ with $\mathrm{HBr}$ gives the product 63a of $\mathrm{N}-\mathrm{C} 1$ bond scission with no trace of the ring expansion product 64a. Under the same conditions compound 64b, the product of 1,5benzothiazepine 62b ring enlargement and sequential hydrolysis, was observed and isolated in $5 \%$ yield (Scheme 14$).{ }^{32}$<smiles>[X]c1ccccc1N1C(Cl)(Cl)C1(Cl)c1ccccc1</smiles>

62a, $X=0$

62b, $X=S$
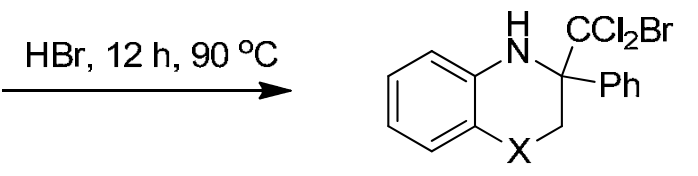

63a, $X=0,62 \%$

63b, $X=S, 45 \%$<smiles>[X]c1ccccc1NC(=O)C(Br)(c1ccccc1)c1ccccc1</smiles>

64a, $X=0,0 \%$ 64b, $X=S, 5 \%$

\section{Scheme 14}

Compounds $65,{ }^{33}$ rapidly undergo aziridine ring cleavage followed by elimination of pyrazole leaving group, analogous to previously reported, ${ }^{34} \mathrm{MeO}$-derivatives, when treated with tetrabutylammonium fluoride (Scheme 15). Ester and aryl substitution on $\mathrm{R}_{2}$ stabilize a negative charge and pyridones $\mathbf{6 6}$ are formed as exclusive products of $\mathrm{C} 6-\mathrm{C} 7$ bond cleavage. In the case of $\mathrm{R}_{2}=\mathrm{H}$, the negative charge cannot be delocalized and cleavage of C6-N1 bond occurs with expansion to the seven membered ring 67. 


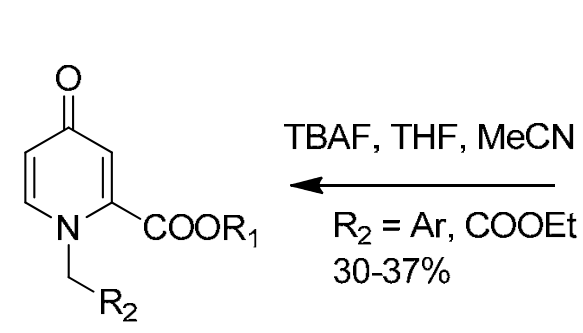

66

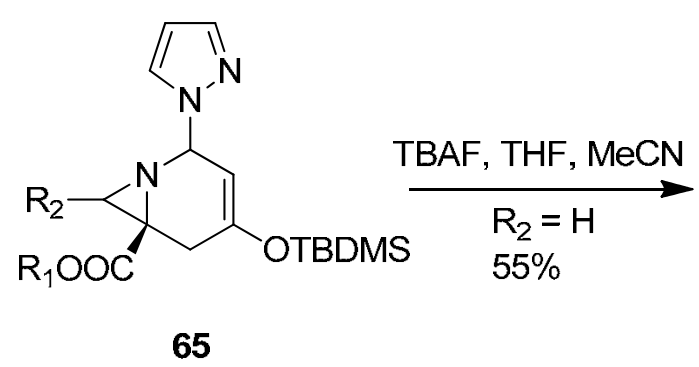

65<smiles>[R]OC1=CC(=O)C=CNC1</smiles>

67

\section{Scheme 15}

Synthesis of aziridine 69 was reported starting from 0 -azidobenzaldehyde 68 through a synthetic sequence which includes fully diastereoselective 1,3-dipolar cycloaddition and irradiation of triazoline intermediate. Although compound 69 is surprisingly stable, as compared to other allylsilane-derived aziridines, its exposure to $\mathrm{TBAF}$ or $\mathrm{Bu}_{4} \mathrm{NOH}$ in $\mathrm{DMF}$ at $-20{ }^{\circ} \mathrm{C}$ promotes conversion to benzazepenol 70 (Scheme 16). ${ }^{35}$ Similarly, starting from $O$ azidophenylacetaldehyde through aziridine intermediate $\mathbf{7 1}$ azocenol 72 was isolated as ca. 5:1 mixture with unsaturated aziridine 73. The formation of the latter was attributed to the side Peterson olefination reaction.<smiles></smiles>

68

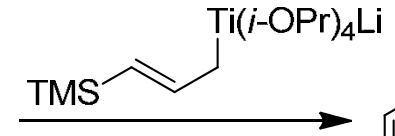

1. THF, $-78^{\circ} \mathrm{C}$

2. toluene, $90^{\circ} \mathrm{C}$

3. $h v$, benzene, rt, $15 \mathrm{~min}$<smiles>N#CC1C(O)c2ccccc2N2CC12</smiles>

69<smiles>OC1C=CCNc2ccccc21</smiles>

70<smiles>CC(C)C1C(O)Cc2ccccc2N2CC12</smiles>

71

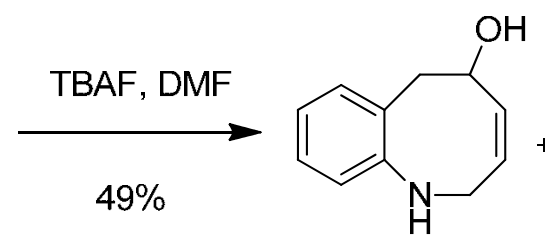

72<smiles>C1=C[C@H]2CN2c2ccccc2C1</smiles>

73

\section{Scheme 16}

The same ring opening strategy was used in the synthesis of the antitumor agent FR-66979, structurally related to the mitomycins (Scheme 17). ${ }^{36}$ 
<smiles>O=C(O)C1C(O)[C@H](Cc2ccccc2)c2c(O)cc(COc3ccccc3)cc2N2CC12</smiles>

74<smiles>OC1C=CCNc2cc(COCc3ccccc3)cc(OCc3ccccc3)c2C1Cc1ccccc1</smiles>

75<smiles>NC(=O)OC[C@H]1c2c(O)cc(CO)cc2N2CC3NC3C1O2</smiles>

FR-66979

\section{Scheme 17}

\section{Ring expansions of aziridines fused to bridged and bicyclic ring systems}

The reactivity of aziridines fused to bicyclic systems is in accordance with the general rules described above. Thus, reaction of diastereomeric iodide $\mathbf{7 6}$ with AgOAc in toluene gives an inseparable 45:55 mixture of the pyrrolidine 77 and piperidine $\mathbf{7 8}$ acetates in $82 \%$ overall yield. The suggested mechanism includes the formation of an intermediate aziridinium ion. In the proof of concept experiment, treatment of the iodide 76 with $\mathrm{AgBF}_{4}$ gave a quantitative yield of aziridinium derivative 79, which upon reaction with NaOAc in toluene gave a 45:55 mixture of the acetates 77 and $\mathbf{7 8}$ in $62 \%$ isolated yield (Scheme 18). ${ }^{37}$

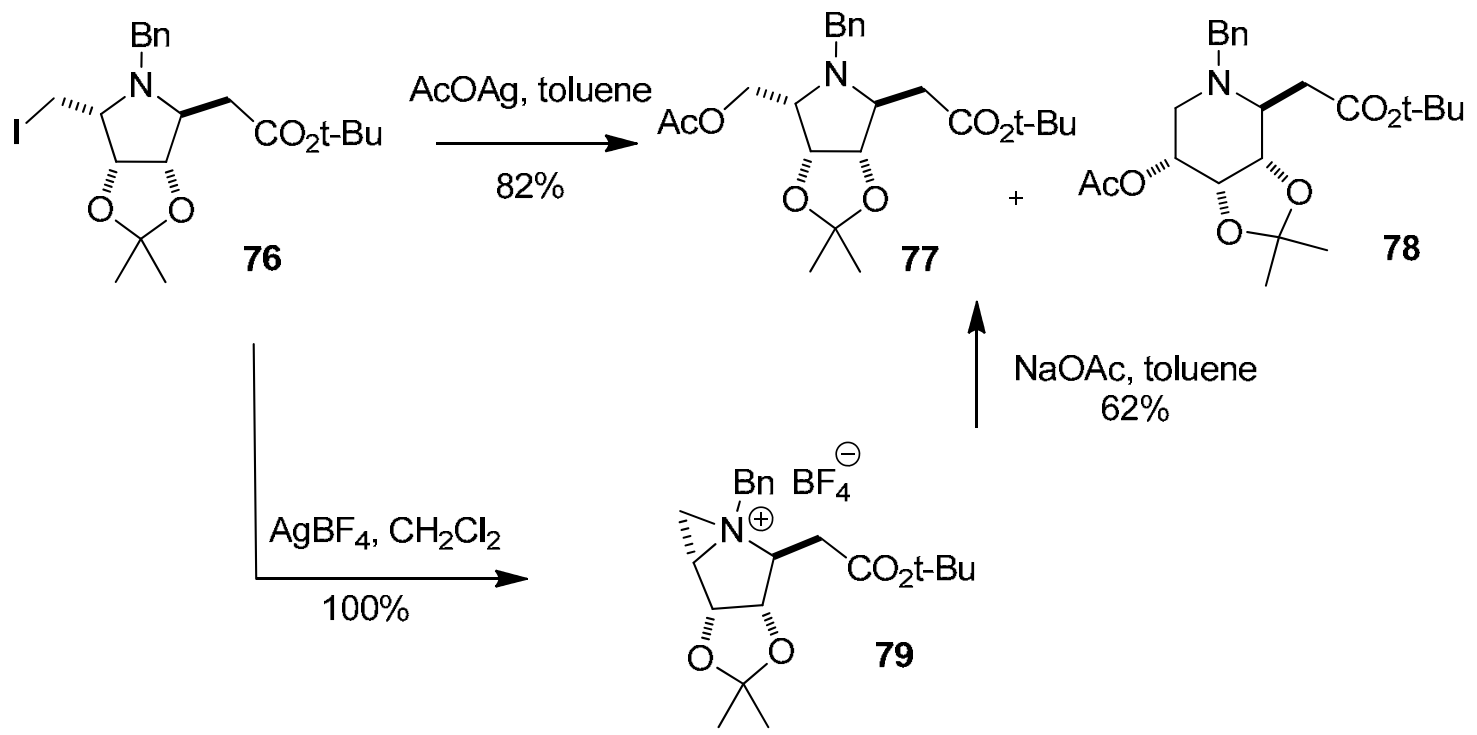

\section{Scheme 18}

Tricyclic salt $\mathbf{8 1}$ bridged through aziridine nitrogen was generated in situ in $\mathrm{CDCl}_{3}$ and characterized by NMR spectroscopy and it demonstrated similar reactivity (Scheme 19). The ring-opening of $\mathbf{8 1}$ with the iodide, methylthiolate, and acetate ions gives indolizidines $\mathbf{8 2}$ and 
quinolizidines 83 in a 1:2 ratio. The formation of quinolizidines as major products indicates a preferential attack of the nucleophile at the most substituted carbon atom C-3 (pathway B) probably due to the larger relief of ring strain. ${ }^{38}$

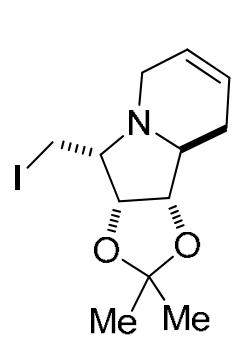

80

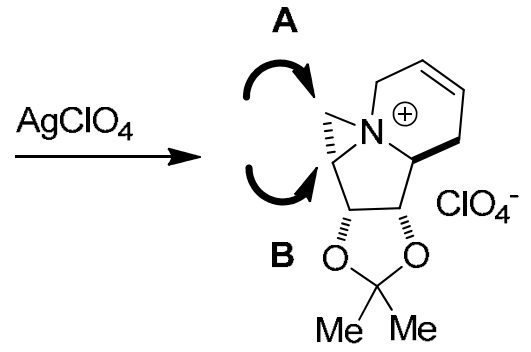

81

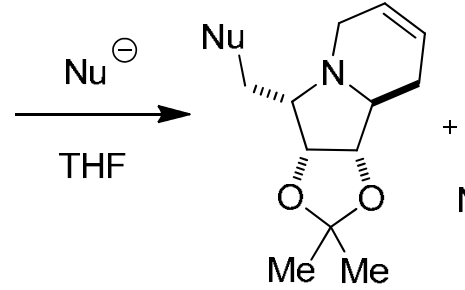

82

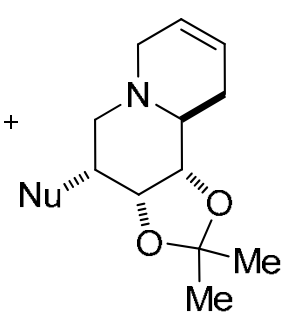

83

\begin{tabular}{|c|c|c|}
\hline $\mathrm{Nu}$ & Reagent & Yield $(82+83), \%$ \\
\hline I & $\mathrm{Bu}_{4} \mathrm{NI}$ & 76 \\
\hline $\mathrm{SMe}$ & NaSMe & 59 \\
\hline OAc & $\mathrm{Bu}_{4} \mathrm{NOAC}$ & 53 \\
\hline
\end{tabular}

\section{Scheme 19}

Bromination of 2-alkyl-2-azabicyclo[2.2.1]hept-5-ene $\mathbf{8 4}$ affords 3-bromo-1-alkyl-1azoniatricyclo 2.2.1.02,6] heptane bromides 85, and opening of the aziridine ring in this salt with various nucleophiles gives the corresponding 6-substituted 2-alkyl-2-azabicyclo[2.2.1] heptanes as exemplified in Scheme 20 for 6-methoxy derivatives 8 86. $^{39 \mathrm{a}-\mathrm{b}}$ Complete inversion of configuration of the ring system occurs due to the fact that only the less sterically hindered bond of the aziridinium bromide $\mathbf{8 5}$ is available for $\mathrm{S}_{\mathrm{N} 2}$ nucleophilic attack.

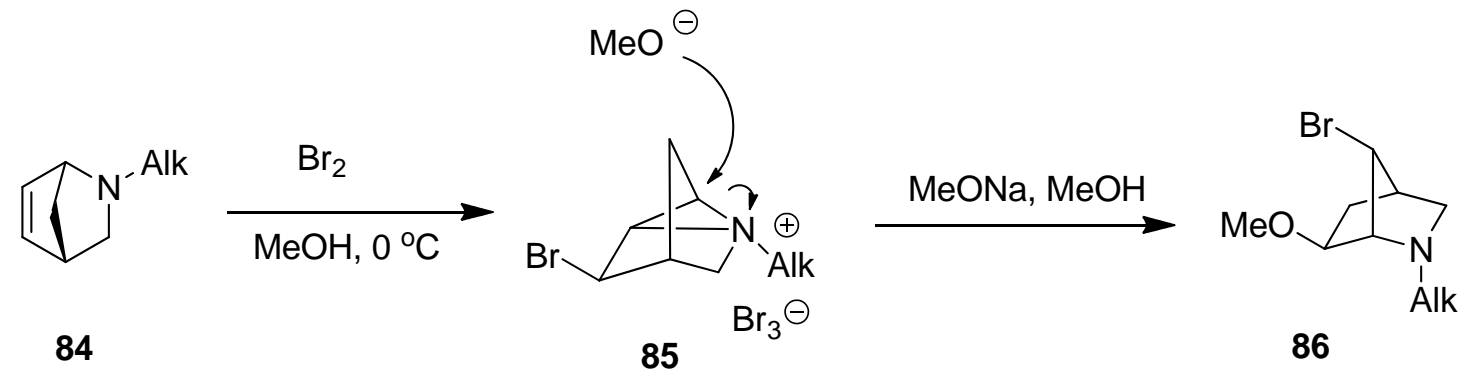

\section{Scheme 20}

Similarly, an efficient method for the preparation of 6-substituted 7-bromo-azabicyclo[2.2.1] heptanes $\mathbf{8 8}$ through the selective opening of the aziridinium $\mathbf{8 7}$ with organocuprates was reported in up to $90 \%$ yields (Scheme 21 ). ${ }^{40}$ 


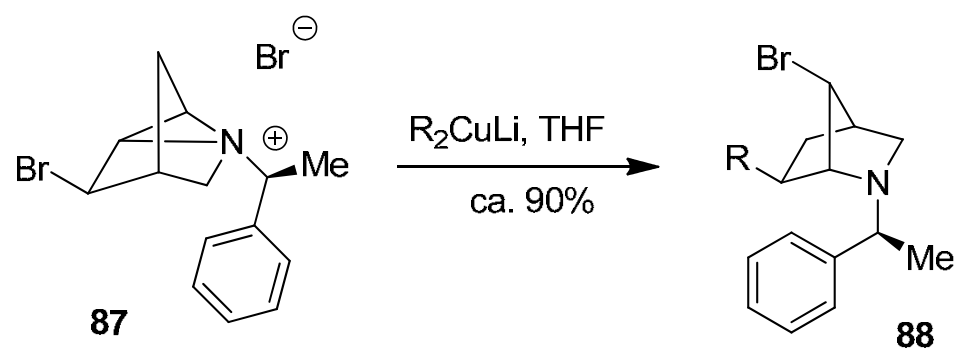

\section{Scheme 21}

Hindered aziridine $\mathbf{8 9}$ is stable towards nucleophilic attack and in alkaline media. Nevertheless, its hydrogenation occurs quantitatively at the less hindered $\mathrm{C} 2-\mathrm{N}$ bond to afford 1,3,3-trimethyl-2-azabicyclo[2.2.2] octane 90, azacineole, one of the components of eucalypt leaf oil (Scheme 22). ${ }^{41}$

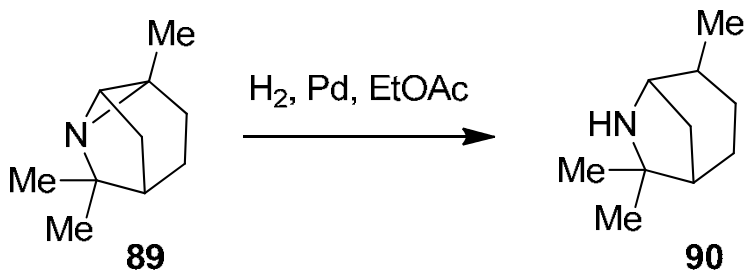

\section{Scheme 22}

On the other hand, more accessible strained aziridine moiety in the bridged 1azabicyclo[4.1.0]heptane 91 easily undergoes stereoselective ring opening by magnesium bromide (as well as other magnesium halides) to produce chiral ester 92 in 55\% yield (Scheme $23){ }^{42 a-b}$<smiles>C[C@H]1CC[C@H](OC(=O)C23CC2C2C=CN(C2)C3)[C@H](c2ccccc2)C1</smiles>

91

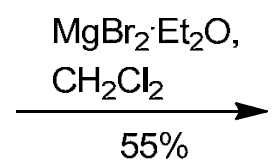<smiles>CC1CCC(C(C)(C)c2ccccc2)C(OC(=O)C2(Br)CNC3C=CC2C3)C1</smiles>

92

\section{Scheme 23}




\section{Summary}

The past decade has witnessed a growing interest in non-aromatic cyclic amines as related to natural product synthesis. The need for new and more efficient synthesis has served as the driving force for research efforts and resulted in non-trivial ring construction strategies, and ring expansion of 1-azabicyclo[n.1.0]alkanes is undoubtedly among them. The present review has outlined the importance of this transformation as an advantageous methodology for synthesis of diverse pyrrolidines, piperidines and medium size cyclic amines.

\section{Acknowledgments}

We thank Dr. Brian Gregg and Dr. Jolicia Gauuan for discussions and advice.

\section{References}

1. (a) Bremner, J. B. In Progress in Heterocyclic Chemistry; Gribble, G. W.; Joule, J. A. Eds.; Elsevier: Oxford, 2004; Vol. 16, p 431. (b) Bremner, J. B. In Progress in Heterocyclic Chemistry; Gribble, G. W.; Joule, J. A. Eds.; Elsevier: Oxford, 2005; Vol. 17, p 389. (c) Quirion, J.-C.; Leclerc, E.; Jubault, P. In Science of Synthesis, Houben-Weyl Methods of Organic Transformations; Molander, G., Ed.; Georg Thieme Verlag: Stuttgart, 2007; Vol. 20, p 659. (d) Fraser, H. L.; Floyd, M. B.; Hopper, D. W. In Progress in Heterocyclic Chemistry; Gribble, G. W.; Joule, J. A. Eds.; Elseveir: Oxford, 2007; Vol. 18, p 310.

2. Kaellstroem, S.; Leino, R. Bioorg. Med. Chem. 2008, 16, 601.

3. (a) Companyo, X.; Alba, A.-N.; Rios, R. Targets Heterocycl. Syst. 2009, 13, 147. (b) Troin, Y.; Sinibaldi, M.-E. Targets Heterocycl. Syst. 2009, 13, 120.

4. Wahba, A. E.; Hamann, M. T. Marine Drugs 2010, 8, 2395.

5. (a) Merino, P.; Delso, I.; Marca, E.; Tejero, T.; Matute, R. Curr. Chem. Biology 2009, 3, 253.

(b) Vogel, P.; Gerber-Lemaire, S.; Juillerat-Jeanneret, L. In Iminosugars Compain, P.; Martin, O. R. Eds.; John Wiley and Sons 2007, 87.

6. Koulocheri, S. D.; Pitsinos, E. N.; Haroutounian, S. A. Curr. Org. Chem. 2008, 12, 1454.

7. Yamashita, Y.; Kobayashi, S. In Handbook of Cyclization Reactions Ma, S., Ed.; Wiley, Inc. 2010, Vol. 1, p 59.

8. Katritzky, A. R.; Rachwal, S. Chem. Rev. 2010, 110, 1564.

9. (a) Vicario, J. L.; Badia, D.; Carrillo, L.; Ruiz, N.; Reyes, E. Targets Heterocycl. Syst. 2008, 12, 302. (b) 2009MI139 Troin, Y.; Sinibaldi, M.-E. In Synthesis of Nitrogen Heterocycles, Royer, J. Ed.; Wiley-VCH Verlag GmbH and Co KGaA: Weinheim, 2009, 139.

10. Remuson, R.; Gelas-Mialhe, Y. Mini-Reviews Org. Chem. 2008, 5, 193. 
11. (a) Cossy, J.; Pardo, D. G. Chemtracts 2002, 15, 579. (b) Cossy, J.; Pardo, D. G. Targets Heterocycl. Syst. 2002, 6, 1.

12. Pearson, W. H.; Lian, B. W. In Comprehensive Heterocyclic Chemistry II, A. R. Katritzky, C. W. Rees, E. F. V. Scriven, Eds.; Pergamon: Oxford, 1996, vol. 1, p 1.

13. Joucla, M.; Fouchet, B.; Hamelin, J. Tetrahedron 1985 41, 2707.

14. (a) Couty, F.; Durrat, F.; Prim, D. Tetrahedron Lett. 2003, 44, 5209. (b) Durrat, F.; Sanchez, M. V.; Couty, F.; Evano, G.; Marrot, J. Eur. J. Org. Chem. 2008, 19, 3286.

15. Drouillat, B.; Couty, F.; David, O.; Evano, G.; Marrot, J. Synlett 2008, 9, 1345.

16. R. C. Fuson, C. L. Zirkle, J. Am. Chem. Soc. 1948, 70, 2760.

17. (a) Roudeau, R.; Pardo, D. G.; Cossy, J. Tetrahedron 2006, 62, 2388. (b) Brandi, A.; Cicchi, S.; Paschetta, V.; Pardo, D. G.; Cossy, J. Tetrahedron Lett. 2002, 43, 9357. (c) Lonkar, P. S.; Kumar, V. A. Bioorg. Med. Chem. Lett. 2004, 14, 2147.

18. Heindl, C.; Hubner, H.; Gmeiner, P. Tetrahedron: Asymmetry 2003, 14, 3153.

19. D'hooghe, M.; Baele, J.; Contreras, J.; Boelens, M.; De Kimpe, N. Tetrahedron Lett. 2008, 49, 6039.

20. Mena, M.; Bonjoch, J.; Gomez-Pardo, D.; Cossy, J. J. Org. Chem. 2006, 71, 5930.

21. (a) Dechamps, I.; Pardo, D. G.; Cossy, J. Synlett 2007, 263. (b) Dechamps, I.; Pardo, D. G.; Cossy, J. Eur. J. Org. Chem. 2007, 4224.

22. Dechamps, I.; Pardo, D. G.; Cossy, J. Tetrahedron 2007, 63, 9082.

23. Ori, M.; Toda, N.; Takami, K.; Tago, K.; Kogen, H. Tetrahedron 2005, 61, 2075.

24. Deyine, A.; Delcroix, J.-M.; Langlois, N. Heterocycles 2004, 64, 207.

25. Dondoni, A.; Richichi, B.; Marra, A.; Perrone, D. Synlett 2004, 1711.

26. Cossy, J.; Mirguet, O.; Pardo, D.G.; Desmurs, J.-R. Tetrahedron Lett. 2001, 42, 5705.

27. Cossy, J.; Mirguet, O.; Pardo, D. G.; Desmurs, J.-R. Eur. J. Org. Chem. 2002, 3543.

28. Brown, D.; Brown, G. A.; Andrews, M.; Large, J. M.; Urban, D.; Butts, C. P.; Hales, N. J.; Gallagher, T. J. Chem. Soc., Perkin Trans. 1 2002, 17, 2014.

29. (a) Khlebnikov, A. F.; Novikov, M. S.; Amer, A. A. Russ. Chem. Bull, Int. Ed. 2004 53, 1092. (b) Khlebnikov, A. F.; Novikov, M. S.; Amer, A. A. Tetrahedron Lett. 2002, 43, 8523.

30. Beduerftig, S.; Wuensch, B. Eur. J. Med. Chem. 2006, 41, 387.

31. Fesenko, A. A.; Tullberg, M. L.; Shutalev, A. D. Tetrahedron 2009, 65, 2344.

32. Shinkevich, E. Yu.; Novikov, M. S.; Khlebnikov, A. F. Synthesis 2007, 225.

33. Alves, M. J.; Fortes, A. G.; Costa, F. T.; Duarte, V. C. M. Tetrahedron 2007, 63, 11167.

34. Alves, M. J.; Gilchrist, T. L. Tetrahedron Lett. 1998, 39, 7579.

35. Ducray, R.; Cramer, N.; Ciufolini, M. A. Tetrahedron Lett. 2001, 42, 9175.

36. Ducray, R; Ciufolini, M. A. Angew. Chem. Int. Ed. 2002, 41, 4688.

37. Davies, S. G.; Nicholson, R. L.; Price, P. D.; Roberts, P. M.; Smith, A. D. Synlett 2004, 901.

38. Verhelst, S. H. L.; Martinez, B. P.; Timmer, M. S. M.; Lodder, G.; van der Marel, G. A.; Overkleeft, H. S.; van Boom, J. H. J. Org. Chem. 2003, 68, 9598.

39. (a) Bulanov, M. N.; Sosonyuk, S. E.; Zyk, N. V.; Zefirov, N. S. Russ. J. Org. Chem. (Transl. Zhurn. Org. Khimii) 2003, 39, 415. (b) Krow, G. R.; Gandla, D.; Guo, W.; Centafont, R. A.; 
Lin, G.; DeBrosse, C.; Sonnet, P. E.; Ross III, C. W.; Ramjit, H. G. Carroll, P. G. Cannon, K. C. J. Org. Chem. 2008, 73, 2114.

40. Gayet, A.; Andersson, P. G. Adv. Synth. Catal. 2005, 347, 1242.

41. Carman, R. M.; Derbyshire, R. P. C. Aust. J. Chem. 2003, 56, 319.

42. (a) Timén, Å. S.; Somfai, P. J. Org. Chem. 2003, 68, 9958. (b) Timén, Å. S.; Fischer, A.; Somfai, P. Chem. Commun. 2003, 1150.

\section{Author's Biography}

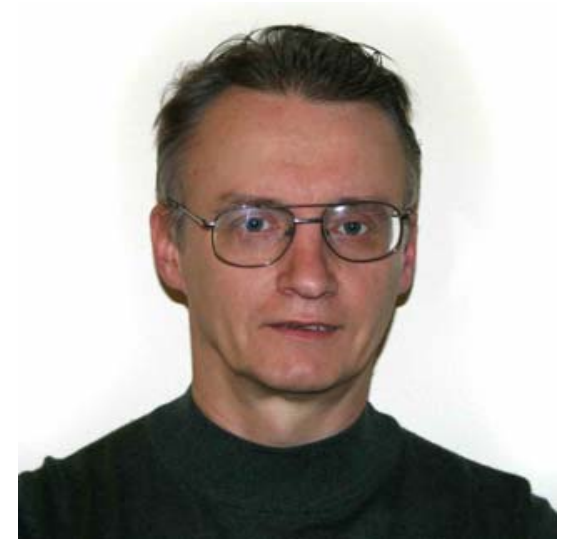

Dmytro O. Tymoshenko received his M.S. chemical engineering from the Ukrainian University of Chemical Engineering (UUCE) of Dnepropetrovsk, Ukraine. Later on, as a Scientist at the Department of Macromolecular Compounds of the UUCE, he received his Ph.D. in 1986, with a thesis focused on synthesis and properties of water soluble polymer careers for drug immobilization and transport. His tenure at UUCE included positions of Assistant Professor and Associate Professor, while his research was focused on various aspects of heterocyclic synthesis and synthesis on polymer supports. His postdoctoral experience was gained with Volodymyr Syromyatnikov at the National Taras Shevchenko University of Kiev, Ukraine, and Alan Katritzky at the University of Florida. In 2000, he joined Albany Molecular Research, Inc. in Albany, New York, as Senior Research Scientist, leading parallel synthetic chemistry research program and working in area of medicinal chemistry. His research interests include synthesis and reactivity of heterocycles, polymer supported reagents and their application in organic synthesis. 